\title{
PENERAPAN ARTIFICIAL NEURAL NETWORK UNTUK KLASIFIKASI FERTILITAS TELUR ITIK MENGGUNAKAN RASPBERRY PI \\ ${ }^{1}$ Jamaludin Indra
}

\author{
${ }^{1}$ Jurusan Teknologi Informatika Fakultas Teknologi dan Ilmu Komputer Universitas Buana \\ Perjuangan Karawang
}

(Jl. H.S Ronggowaluyo Telukjambe Timur Karawang, jamaludin.indra@ubpkarawang.ac.id)

\begin{abstract}
ABSTRAK
Artificial Neural Network (ANN) telah banyak diterapkan pada berbagai bidang, salah satunya penerapan pada bidang peternakan. Penetasan menggunakan mesin penetas telur, proses pengklasifikasian embrio telur menjadi sangat penting dalam proses penetasan untuk membedakan antara yang layak, berdasarkan adanya perkembangan embrio yang dapat dilanjutkan dalam proses inkubasi atau tidak layak (fertile atau infertile), dalam penelitian ini menyajikan klasifikasi menggunakan teknik pengolahan citra digital menggunakan metode artificial neural network yang diaplikasikan pada Raspberry Pi sebagai pemroses gambar dan menampilkan hasil klasifikasi. Dengan metode artificial neural network dan penggunaan Raspberry Pi mampu mencapai akurasi pendeteksian 95\%.

Kata kunci: Artificial Neural Network, Pengolahan Citra Digital, Embrio, Klasifikasi, Telur .
\end{abstract}

\begin{abstract}
Artificial Neural Network (ANN) has been widely applied in various fields, one of which is the application in the field of animal husbandry. Hatching using an egg incubator machine, the classification process of egg embryos is very important in the hatching process to distinguish between the appropriate, based on the embryonic development that can be continued in the process of incubation or inadequate (fertile or infertile), in this study presents classification using image processing techniques digital uses the artificial neural network method that is applied to the Raspberry Pi as an image processor and displays the classification results. With the artificial neural network method and the use of Raspberry Pi it is expected to be able to achieve $90 \%$ detection accuracy.
\end{abstract}

Key word : Artificial Neural Network, Digital Image Processing, Embriyo, Calssification, Egg. 


\section{PENDAHULUAN}

\section{Latar Belakang}

Perkembangan teknologi sekarang ini sudah semakin canggih, salah satunya yaitu adanya komputer papan tunggal (single board circuit) berukuran kecil sebesar kartu kredit yang dinamakan Raspberry Pi. komputer kecil ini mampu digunakan untuk berbagai keperluan seperti spreadsheet, game, bahkan biasa digunakan sebagai media player karena kemampuannya dalam memutar video high definition. Diakses 28 Maret 2016 (http://raspberry pi.org).

Pada saat ini pengolahan citra digital telah menggunakan Raspberry Pi sebagai alat pengolahan datanya. Penelitian sebelumnya pengambilan gambar sistem tertanam menggunakan Raspberry Pi dengan metode eigen faces, face recognition untuk menemukan persamaan, hasilnya membuktikan bahwa sistem tertanam menggunakan Raspberry Pi lebih kecil dimensinya, konsumsi listrik yang rendah dan mampu mengolah data dan lebih mudah daripada PC-berbasis face recognition (Senthilkumar et al. 2014).

Penelitian sebelumnya juga yaitu implementasi pengolahan citra digital di Raspberry pi dengan metode citra digital untuk mengolah gambar, dengan menggunakan algoritma untuk meningkatkan kualitas gambar Raspberry Pi berhasil mengeksekusi dan mengolah gambar yang sangat berwarna-warni dan berkualitas (Shilpashree et al. 2015).

Penerapan pengolahan citra digital menggunakan Raspberry Pi akan diaplikasikan dalam pendeteksian embrio telur itik. Pada saat ini masih banyak peternak itik masih menggunakan cara manual untuk proses pendeteksian embrio telur itik yang menyita tenaga dan waktu, adapun penelitian sebelumnya telah ada yang menerapkan pengolahan citra digital untuk pendeteksian telur. Pendeteksian embrio telur ayam berdasarkan citra greyscale menggunakan metode k-means automatic thresholding di MATLAB, dengan metode k-means untuk menentukan nilai threshold terbukti mampu untuk mensegmentasikan bentuk embrio ayam berdasarkan citra greyscale-nya sehingga dapat ditentukan apakah telur dalam proses penetasan tersebut fertile atau infertile (Harsadi 2015). Dengan teknik pengolahan citra digital mampu menetukan dimensi kuning telur (diameter kuning telur), mampu memprediksi kantong udara dalam telur, jika dilakukan dengan cara manual hasil akurasi yaitu $81,34 \%$ sedangkan dengan metode neural network algoritma backpropagation hasil akurasinya 83,9\%, algoritma LS-SVM hasil akurasinya mampu mencapai 91.4\%, jadi hasil akhir dari efisiensinya yaitu hampir 80 sampai $85 \%$ dari hasil akurasi manual (Bhunaveshwari \& Palanivelu 2015). 
Artificial neural network digunakan untuk identifikasi biometric retina menghasilkan akurasi 97,50 \% (Sadikoglu \& Uzelaltinbulat 2016).

Berdasarkan penelitian-penelitian diatas bahwa Raspberry Pi bisa diaplikasikan untuk mengolah data citra digital yang akan diaplikasikan pada deteksi embrio telur itik dengan metode artificial neural network dapat mengklasifikasi fertilitas telur itik tersebut.

\section{Rumusan Masalah}

Berdasarkan latar belakang diatas, penelitian yang dilakukan adalah dengan rumusan masalah sebagai berikut:

1. Bagaimana membuat alat untuk mengklasifikasi fertilitas telur itik menggunakan mini komputer Raspberry Pi.

2. Bagaimana membuat alat untuk mengklasifikasi fertilitas telur itik menggunakan metode digital image processing dan artificial neural network untuk meningkatkan keakurasian.

\section{Batasan Masalah}

Agar lebih fokus dan terarah, batasan masalah yang akan dibahas pada penelitian ini adalah sebagai berikut :

1. Citra diambil menggunakan Camera Pi.

2. Citra yang digunakan berbentuk $2 \mathrm{D}$ tidak berotasi.

3. Telur yang menjadi objek penelitian adalah telur itik yang sudah dieramkan minimal tiga hari.

\section{Tujuan}

Tujuan dilakukan penelitian ini adalah sebagai berikut:

1. Merancang sebuah model alat untuk mengidentifikasi dan mengklasifikasi fertilitas telur itik menggunakan Raspberry Pi.

Mengetahui hasil penerapan teknik digital image processing dan artificial neural network dalam mengidentifikasi dan klasifikasi fertilitas telur itik . 


\section{METODE PENELITIAN}

\section{Kerangka Kerja Perangkat Keras}

Seperti disebutkan pada bab sebelumnya untuk langkah awal untuk pengambilan gambar yang menggunakan alat. Oleh karena itu pada tesis ini akan mencoba memepersiapkan kondisi penangkapan gambar yaitu posisi letak kamera yang digunakan, LED USB yang digunakan dalam pencahayaan.

Pada Gambar III-1 menunjukan alur proses dan perangkat yang digunakan, proses awal yaitu Raspberry Pi aktif dan menjalankan aplikasi deteksi telur untuk mulai mengambil video dari camera Pi .telur di tempatkan pada ruang yang gelap, karena untuk menghasilkan gambar yang baik dalam pengambilan gambar telur harus berlatar belakang gelap (Zhu \& Ma 2011). Proses selanjutnya LED akan aktif untuk pencahayaan, setelah itu gambar akan diambil dan diproses oleh Raspberry Pi, hasilnya akan di tampilkan di monitor.

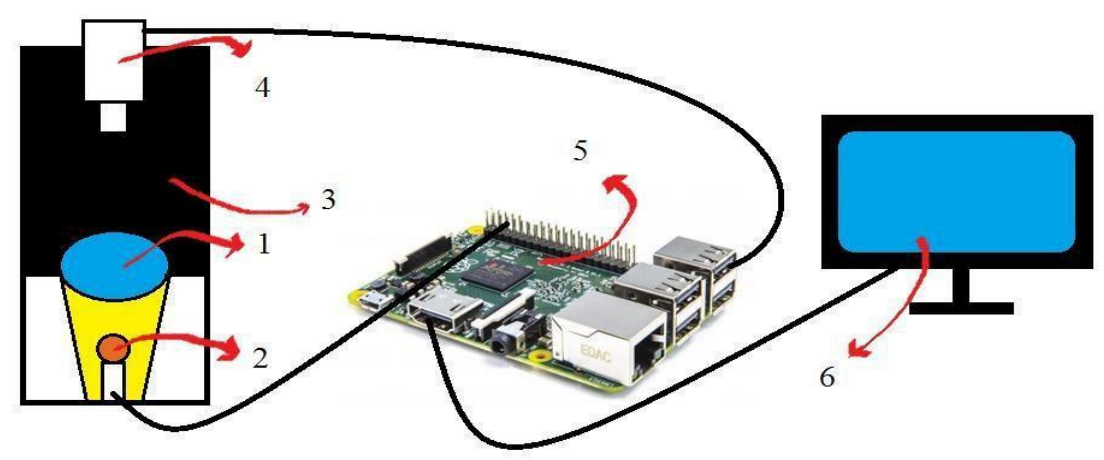

Gambar 1 : Rancangan Perangkat Keras

1. Telur itik : objek yang akan diteliti

2. LED : sebagai sumber cahaya

3. Ruang gelap : ruang yang akan ditempatkan kamera untuk pengambilan gambar.

4. Camera $\mathrm{Pi}$ : perangkat yang akan digunakan untuk pengambilan gambar digital untuk diproses selanjutnya di Raspberry Pi.

5. Papan Raspberry Pi : tempat berjalannya perangkat lunak untuk pemroses data.

6. Display / monitor LCD : perangkat untuk menampilkan hasil dari proses pengolahan citra digital. 
Tabel 1 : Pengaturan Eksperimen

\begin{tabular}{|l|l|}
\hline Sumber cahaya & LED USB light \\
\hline Kamera & Camera Pi \\
\hline Bahasa pemrograman & Python \\
\hline Pengolaah gambar & Raspberry Pi 2 B \\
\hline
\end{tabular}

\section{Kerangka Kerja Perangkat Lunak}

Pada bagian ini dijelaskan langkah demi langkah bagian-bagian penting pembentuk sistem ini. Penerapan pengolaha citra digital dan pengenalan pola. Dibagian ini pula menjelaskan diagram alir dan pandangan umum tentang klasifikasi fertiitas telur itik. Diagram alir yang diusulkan seperti Gambar III- 3.

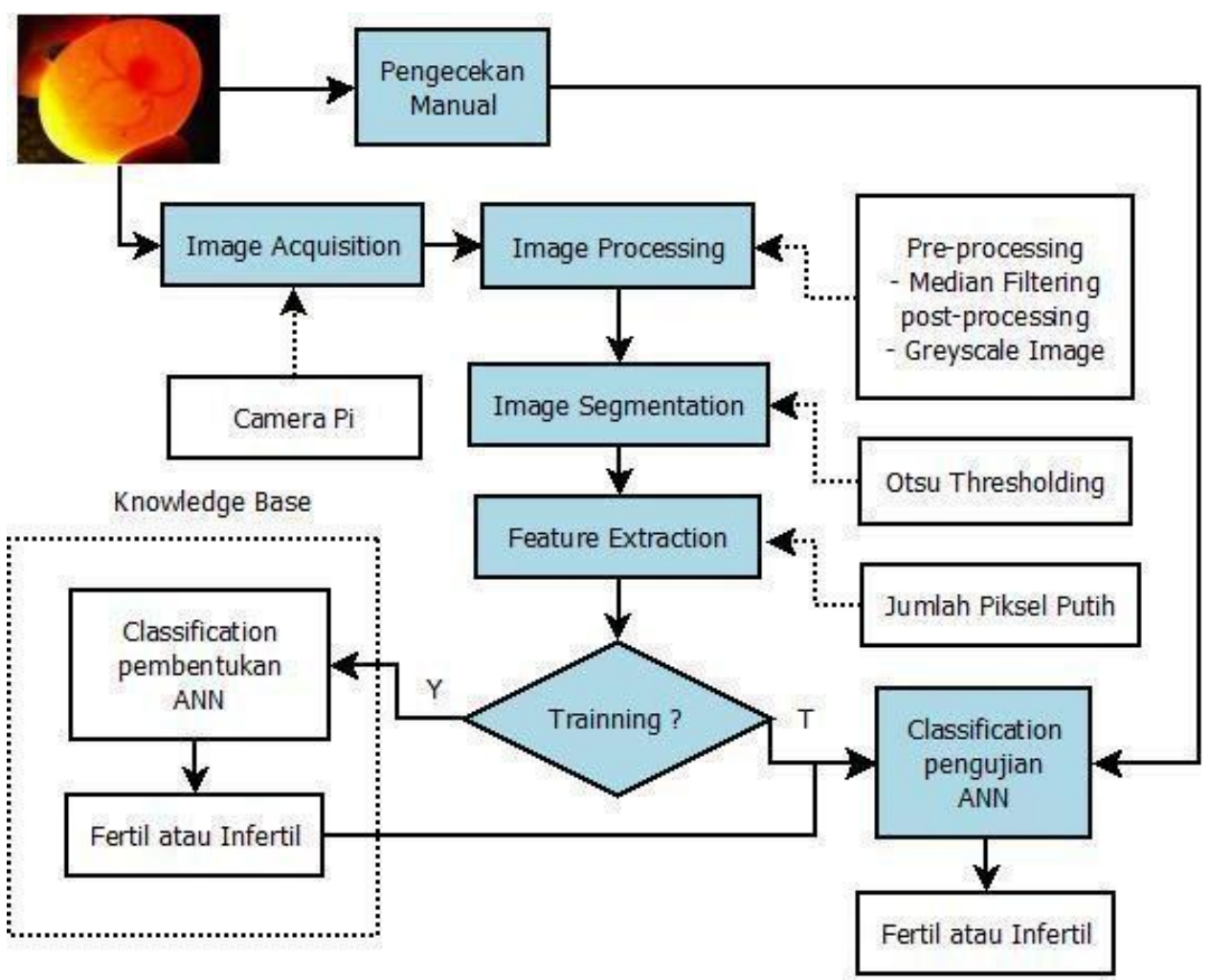

Gambar 2 : Diagram Untuk Klasifikasi Embrio Telur

\section{Image Acquisition}

Pada proses image acquisition penggunaan perangkat keras yang digunakan. Dimana algoritma pengambilan gambar embrio telur itik dipersiapkan.

Dalam gambar 3 algoritma pengambilan gambar dimulai dengan inisialisai semua perangkat. Pertama ketikan sistem diaktifkan akan 
mengambil video ketika tombol Proses ditekan maka sistem akan mengambil satu frame gambar yang akan diproses. Kamera yang digunakan yaitu Camera Pi, gambar yang diambil 640 x 480 piksel. Pada proses ini gambar yang diambil yaitu gambar original RGB.

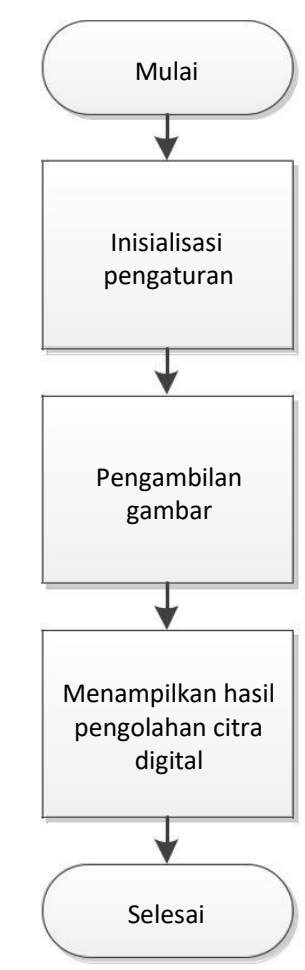

Gambar 3 : Diagram Alir Pengambilan Gambar

\section{Pre-processing}

Pada bagian ini untuk meng-crop objek dan menghilangkan noise, menggunakan teknik filter sebagai teknik untuk menghilangkan noise dan meningkatkan kualitas gambar. Gambar yang diambil awalnya berbentuk RGB selanjutnya di filter dengan teknik median filter, median filter terbukti lebih baik dibandingkan dengan algoritma yang lain untuk menghilangkan noise karena mampu mempertahankan garis tepi dan mudah diimplementasikan (Chandel \& Gupta 2013). Setelah itu gambar dikonversi ke bentuk greyscale untuk menghasilkan gambar berkualitas baik pada proses thresholding.

\section{Segmentation}

Pada langkah ini untuk mengkonversi gambar ke gambar binary digunakan metode Otsu dan diinverse untuk mendapatkan nilai piksel putih, 
metode Otsu telah banyak digunakan dikarenakan lebih sederhana dan memberikan kualitas yang baik (Vala \& Baxi 2013).

Metode Otsu melakukan penyeleksian nilai threshold dari histrogram citra abu-abu. Metode penyeleksian nilai threshold dilakukan dengan memakai pendekatan statistika. Nilai threshold dipilih dari nilai warna keabuan yang terletak pada interval histogram dimana nilai warna keabuan tersebut memaksimalkan nilai fungsi.

\section{Features Extraction}

Untuk mendeteksi embrio telu dengan cara menghitung sebaran piksel putih yang bernilai biner 1, hasil dari proses sebelumnya yaitu segmentasi menggunakan metode otsu. Yaitu nilai dari matrik yang bernilai biner 1 akan dijumlahkan sehingga akan diketahui jumlah sebaran piksel putih.

Penelitian sebelumnya dilakukan untuk mendeteksi kotoran pada telur (Dehrouyeh et al. 2010).

\section{Training}

Fungsi dari tahap ini adalah untuk melakukan training terhadap data latih dan untuk menentukan bobot koneksi di dalam jaringan sehingga jaringan dapat melakukan pemetaan (mapping) dari input ke output sesuai dengan yang di inginkan. Pemetaan ditentukan melalui satu set pola contoh atau data pelatihan

(training data set). Pada pnelitian ini nilai input adalah nilai dari jumlah piksel putih yang dihasilkan dari proses sebelumya yaitu pada proses features extraction.

\section{Classification}

Pada tahap ini nilai hasil dari proses features extraction akan di uji dengan nilai data yang didapatkan dari hasil training dan akan menetukan apakah hsilnya fertile atau infertile.

\section{HASIL PENELITIAN DAN}

\section{PEMBAHASAN Pengumpulan Kebutuhan}

Proses awal dalam penelitian yaitu mengumpulkan alat yang dibutuhkan dalam penelitian. 
Tabel 2 : Kebutuhan Perangkat Keras

\begin{tabular}{|c|l|l|}
\hline No. & \multicolumn{1}{|c|}{ Nama Alat } & Jumlah \\
\hline 1 & Raspberry pi 3B & 1 \\
\hline 2 & Camera pi & 1 \\
\hline 3 & Monitor & 1 \\
\hline 4 & Mouse & 1 \\
\hline 4 & Keyboard & 1 \\
\hline 5 & Kabel HDMI to VGA & 1 \\
\hline 6 & Cassing Raspberry pi + fan & 1 \\
\hline
\end{tabular}

Setelah pengumpulan maka proses selanjutnya adalah perakitan dan instalasi dari Rasperry pi, Sistem Operasi yang digunakan yaitu Raspian Sterch serta diinstal paket pendukung seperti OpenCV, Keras dan TensorFlow untuk system cerdas.

\section{Kotak Teropong}

Kotak teropong dibuat menggunakan bahan Arkrilik dengan latar belakang berwarna hitam, dimaksudkan agar membedakan antara objek telur dengan latar belakang.
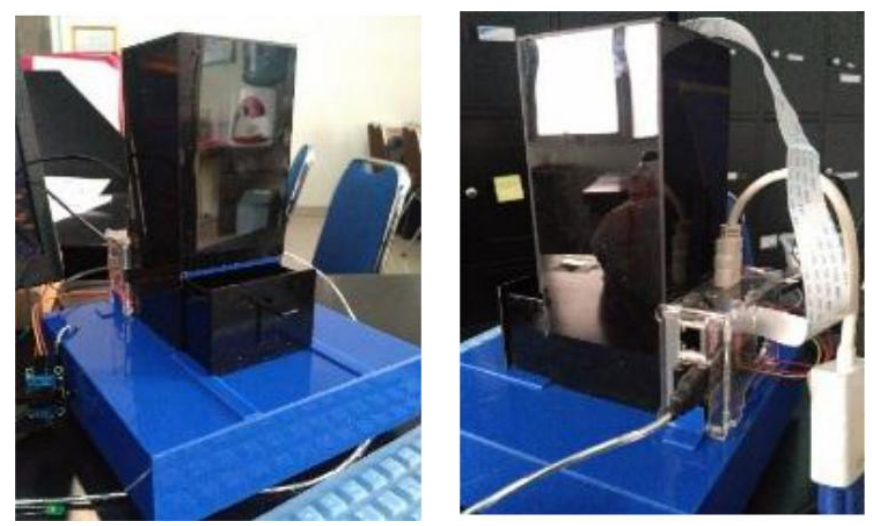

Gambar 4 : Kotak Teropong Telur Itik

\section{Proses Pembuatan Perangkat Lunak}

Pembuatan antarmuka perangkat lunak dilakukan dengan perangkat lunak Glade, file yang dihasilkan ber ekstension xml (.xml) yang nantinya akan dipanggil sebagai antarmuka perangkat lunak. 


\section{Pengelompokan Data, Analisis dan Temuan - Temuan}

Mengacu pada metode pengumpulan data yang dilakukan, maka analisis data pada penelitian ini :

1. Analisis data hasil studi dokumentasi

Data hasil studi dokumentasi yang didapatkan pada penelitian ini adalah data pengujian langsung secara manual yaitu peneropongan dilakukan secara langsung oleh peternak itik, data nilai piksel dan persentase sebaran piksel putih citra uji sesuai standar pada percobaan yang dilakukan beberapa kali untuk mendapatkan nilai batas standar yang akan menjadi batas penentu apakah citra telur infertil atau fertil, maka pengelompokan menjadi tiga kelompok data yaitu :

a) Data uji manual

Data uji manual dilakukan untuk mendapatkan nilai akurasi dari peneropongan telur yang dilakukan secara langsung oleh peternak menggunakan alat sederhana dan menggunakan mata telanjang dengan sampel telur yang sama, dengan jumlah 20 telur dengan komposisi 10 telur fertil dan 10 telur infertil.

Tabel 3 : Hasil Pengujian Manual

\begin{tabular}{|c|c|c|c|}
\hline No.Uji & Kondisi Telur & $\begin{array}{c}\text { Hasil Uji } \\
\text { Manual }\end{array}$ & Keterangan \\
\hline 1 & Fertil & Fertil & Sesuai \\
\hline 2 & Fertil & Fertil & Sesuai \\
\hline 3 & Fertil & Fertil & Sesuai \\
\hline 4 & Fertil & Fertil & Sesuai \\
\hline 5 & Fertil & Fertil & Sesuai \\
\hline 6 & Fertil & Fertil & Sesuai \\
\hline 7 & Fertil & Fertil & Sesuai \\
\hline 8 & Fertil & Fertil & Sesuai \\
\hline 9 & Fertil & Fertil & Sesuai \\
\hline 10 & Fertil & Fertil & Sesuai \\
\hline 11 & Infertil & Fertil & Tidak Sesuai \\
\hline 12 & Infertil & Infertil & Sesuai \\
\hline 13 & Infertil & Fertil & Tidak Sesuai \\
\hline 14 & Infertil & Infertil & Sesuai \\
\hline 15 & Infertil & Infertil & Sesuai \\
\hline 16 & Infertil & Infertil & Sesuai \\
\hline 17 & Infertil & Infertil & Sesuai \\
\hline 18 & Infertil & Infertil & Sesuai \\
\hline 19 & Infertil & Infertil & Sesuai \\
\hline
\end{tabular}




\begin{tabular}{|l|l|l|l|}
\hline 20 & Infertil & Infertil & Sesuai \\
\hline
\end{tabular}

$(\%)=$

$(\%)=\%$

$(\%)=\%$

Pada Tabel 5. 1 menunjukan 20 kali percobaan identifikasi dan klasifikasi pada citra telur infertil menunjukan akurasi sebesar $\mathbf{9 0 \%}$, data uji manual terdapat pada lembar lampiran.

b) Data set yang digunakan dalam sistem

1. Data set telur infertil

Data set yang digunakan untuk data training infertil berjumlah 20 dataset..
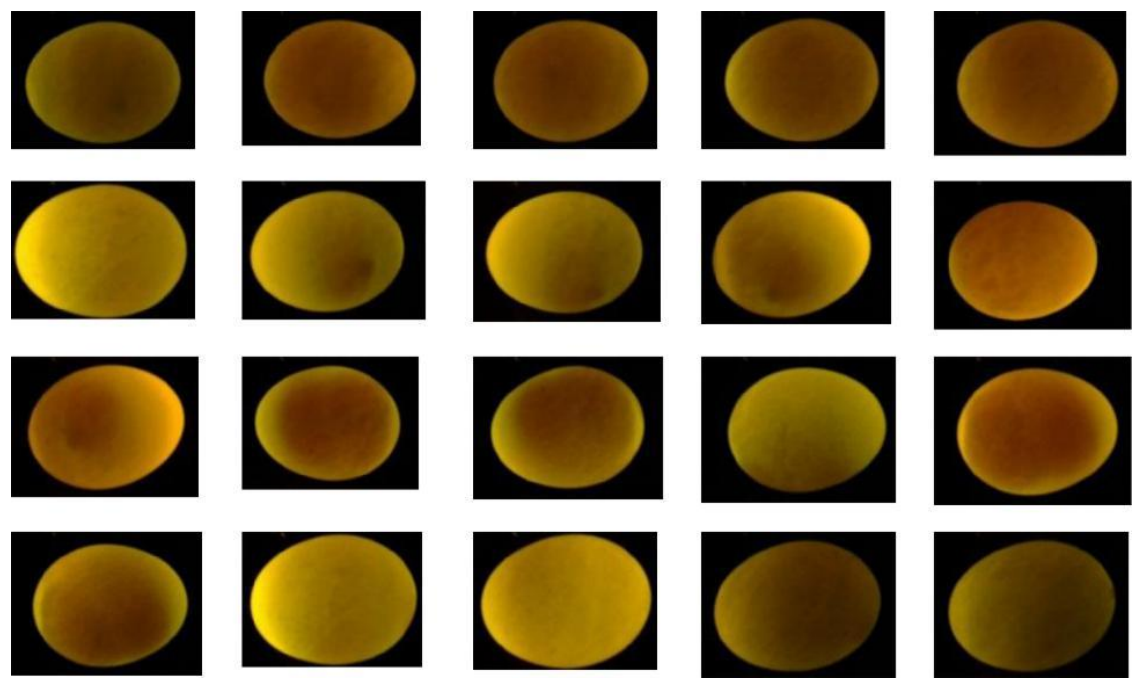

Gambar 5 : Dataset Telur Infertil

2. Dataset telur fertile

Data set yang digunakan untuk data fertil infertil berjumlah 20 dataset.
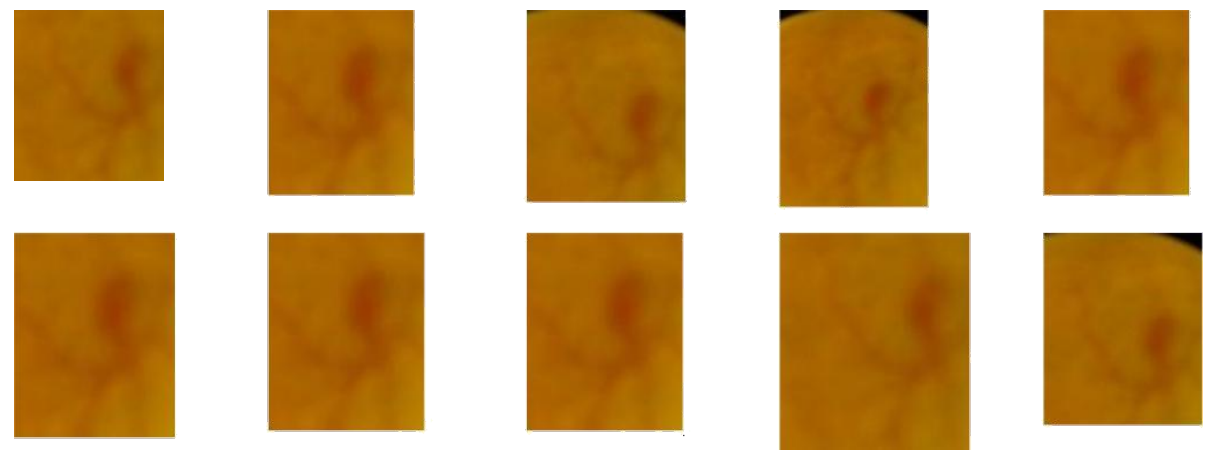


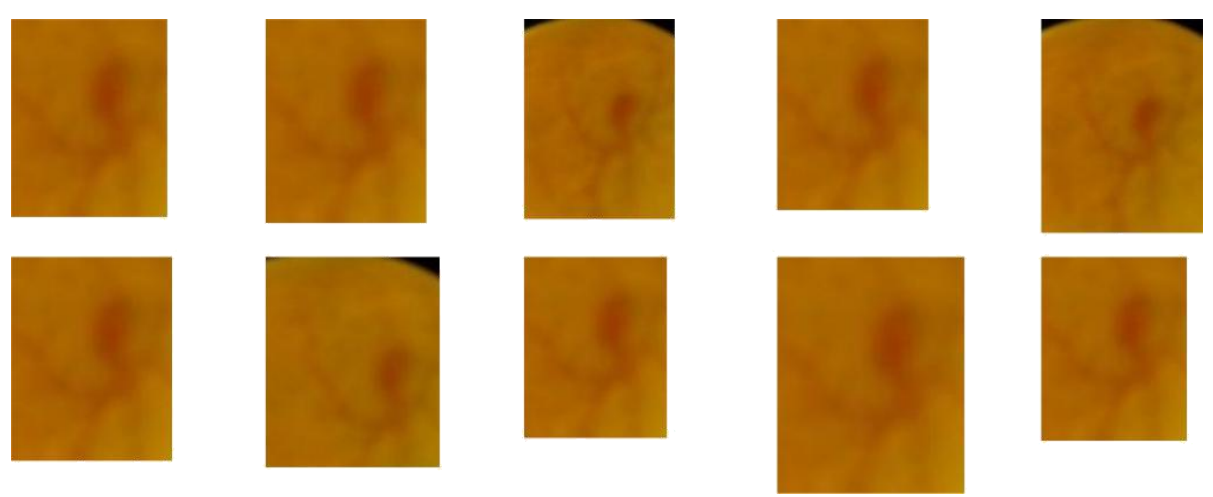

Gambar 6 : Dataset Telur Fertil

2. Tampilan program saat pengujian

Tampilan program saat pengujian, sistem menampilkan informasi pengujian berupa gambar secara langsung, klasifikasi dan angka prediksi.

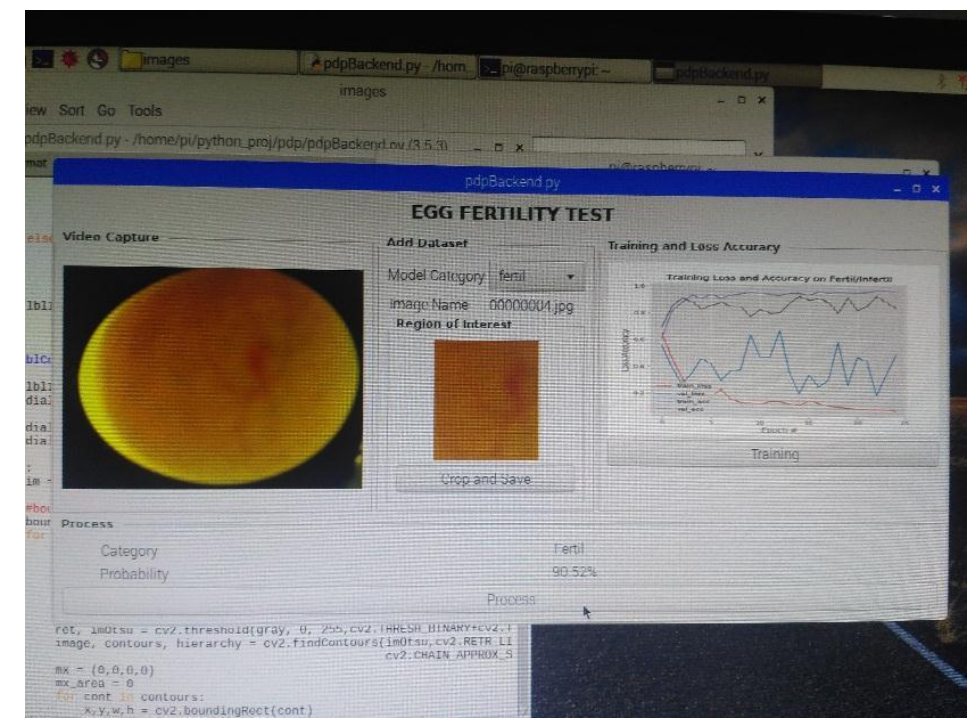

Gambar 7 : Tampilan Program

\section{Hasil pengujian data training}

Jaringan dilatih sebanyak 25 kali dari akurasi 43,75\% sampai dengan mencapai $100 \%$. 


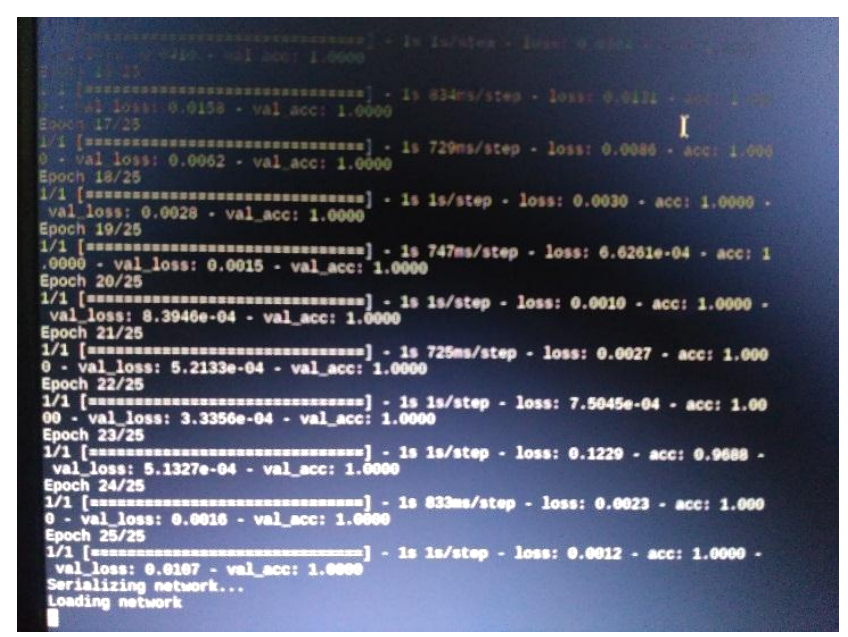

Gambar 8 : Hasil Pengujian Dataset Training

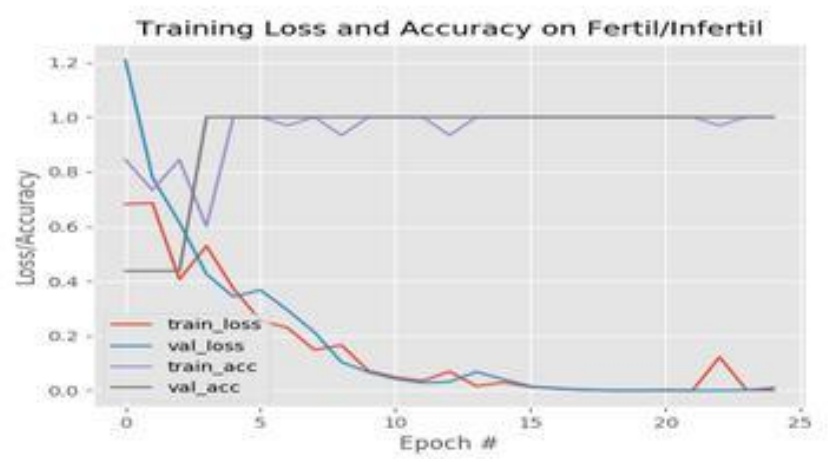

Gambar 9 : Grafik PengujianDataset Training

\section{Pengujian Akurasi Sistem}

1. Pengujian telur infertil

Pengujian akurasi sistem dilakukan dengan beberapa kondisi untuk mendapatkan hasil pengujian yang berbeda-beda, jumlah percobaan pada setiap kondisi dilakukan sebanyak 20 kali percobaan.

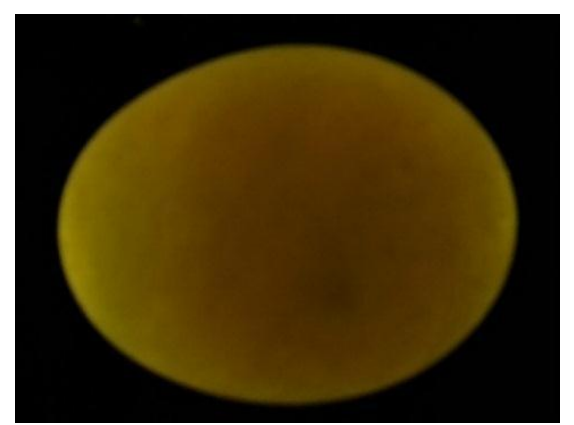

Gambar 10 : Telur Infertil 
Tabel 4 : Hasil Pengujian Manual

\begin{tabular}{|c|c|c|c|c|}
\hline No.Uji & Kondisi Telur & Nilai Prediksi & Hasil & Keterangan \\
\hline 1 & Infertil & 99,66 & Infertil & Sesuai \\
\hline 2 & Infertil & 99,67 & Infertil & Sesuai \\
\hline 3 & Infertil & 99,65 & Infertil & Sesuai \\
\hline 4 & Infertil & 99,67 & Infertil & Sesuai \\
\hline 5 & Infertil & 99,66 & Infertil & Sesuai \\
\hline 6 & Infertil & 99,65 & Infertil & Sesuai \\
\hline 7 & Infertil & 99,67 & Infertil & Sesuai \\
\hline 8 & Infertil & 99,60 & Infertil & Sesuai \\
\hline 9 & Infertil & 99,65 & Infertil & Sesuai \\
\hline 10 & Infertil & 99,65 & Infertil & Sesuai \\
\hline 11 & Infertil & 99,67 & Infertil & Sesuai \\
\hline 12 & Infertil & 99,66 & Infertil & Sesuai \\
\hline 13 & Infertil & 99,65 & Infertil & Sesuai \\
\hline 14 & Infertil & 99,64 & Infertil & Sesuai \\
\hline 15 & Infertil & 99,66 & Infertil & Sesuai \\
\hline 16 & Infertil & 88,32 & Fertil & Tidak Sesuai \\
\hline 17 & Infertil & 99,66 & Infertil & Sesuai \\
\hline 18 & Infertil & 99,64 & Infertil & Sesuai \\
\hline 19 & Infertil & 99,64 & Infertil & Sesuai \\
\hline 20 & Infertil & 99,66 & Infertil & Sesuai \\
\hline \multirow{2}{*}{$\% \%$} \\
$(\%)=$
\end{tabular}

Pada Tabel IV- 5 menunjukan 20 kali percobaan identifikasi dan klasifikasi pada citra telur infertil menunjukan akurasi sebesar $\mathbf{9 5 \%}$, keseluruhan uji infertil terdapat pada lembar lampiran.

2. Pengujian telur fertil

Tabel 5 : Pngujian Telur Infertil

\begin{tabular}{|c|c|c|c|c|}
\hline No.Uji & $\begin{array}{c}\text { Kondisi } \\
\text { Telur }\end{array}$ & Nilai Prediksi & Hasil & Keterangan \\
\hline 1 & Fertil & 99,70 & Fertil & Sesuai \\
\hline 2 & Fertil & 99,76 & Fertil & Sesuai \\
\hline 3 & Fertil & 99,77 & Fertil & Sesuai \\
\hline 4 & Fertil & 99,75 & Fertil & Sesuai \\
\hline
\end{tabular}




\begin{tabular}{|c|c|c|c|c|}
\hline 5 & Fertil & 99,76 & Fertil & Sesuai \\
\hline 6 & Fertil & 99,75 & Fertil & Sesuai \\
\hline 7 & Fertil & 99,74 & Fertil & Sesuai \\
\hline 8 & Fertil & 99,76 & Fertil & Sesuai \\
\hline 9 & Fertil & 99,76 & Fertil & Sesuai \\
\hline 10 & Fertil & 99,74 & Fertil & Sesuai \\
\hline 11 & Fertil & 99,75 & Fertil & Sesuai \\
\hline 12 & Fertil & 99,76 & Fertil & Sesuai \\
\hline 13 & Fertil & 99,76 & Fertil & Tidak Sesuai \\
\hline 14 & Fertil & 99,77 & Fertil & Sesuai \\
\hline 15 & Fertil & 99,77 & Fertil & Sesuai \\
\hline 16 & Fertil & 99,76 & Fertil & Sesuai \\
\hline 17 & Fertil & 99,76 & Fertil & Sesuai \\
\hline 18 & Fertil & 84,56 & Infertil & Tidak Sesuai \\
\hline 19 & Fertil & 99,74 & Fertil & Sesuai \\
\hline 20 & Fertil & 99,76 & Fertil & Sesuai \\
\hline
\end{tabular}

$(\%)=\%$
$(\%)=$
$(\%)=\%$

Pada Tabel IV- 6 menunjukan 20 kali percobaan identifikasi dan klasifikasi pada citra telur fertile menunjukan akurasi sebesar $\mathbf{9 0 \%}$, keseluruhan uji infertil terdapat pada lembar lampiran.

\section{KESIMPULAN DAN SARAN}

\section{Kesimpulan}

Kesimpulan yang diperoleh dari hasil penelitian pendahuluan yang telah dilakukan menunjukan bahwa Raspberry pi bisa digunakan untuk menjalankan perangkat lunak menggunakan pustaka openCV, Keras dan TensorFlow, maka dapat disimpulkan bahwa dengan adanya alat ini untuk mengklasifikasi fertilitas telur itik menggunakan Raspberry Pi mampu mengklasifikasi dengan akurasi untuk telur infertile $\mathbf{9 5 \%}$ dan telur fertile $\mathbf{9 5 \% .}$ 


\section{Saran}

a. Untuk pencapaian akurasi yang maksimal dapat ditingkatkan dengan menggunakan lampu penerngan yang lebih terang agar kualitas gambar lebih jelas dan tajam.

b. Kotak yang digunakan harus lebih baik sehingga gambar lebih jelas.

c. Jumlah dataset ditambah untuk meningkatkan hasil akurasi

\section{DAFTAR PUSTAKA}

Bhunaveshwari, M.. \& Palanivelu, L.., 2015. Improvement In Detection Of Chicken Egg Fertility Using Image Processing. International Journal On Engineering Technology and Sciences - IJETS, 2(4), pp.64-67.

Chandel, R. \& Gupta, G., 2013. Image Filtering Algorithms and Techniques : A Review. ,3(10), pp.198-202.

Dehrouyeh, M.H. et al., 2010. Grading and Quality Inspection of Defected Eggs Using Machine Vision. , 17(2005), pp.23-30.

Harsadi, P., 2015. Deteksi Embrio Ayam Berdasarkan Citra Grayscale Menggunakan KMeans Automatic Thresholding. Jurnal Ilmiah SINUS, pp.49-56.

Sadikoglu, F. \& Uzelaltinbulat, S., 2016. Biometric retina identification based on neural network. Procedia - Procedia Computer Science, 102(August), pp.26-33. Available at: http://dx.doi.org/10.1016/j.procs.2016.09.365.

Senthilkumar, G., Gopalakrishnan, K. \& Kumar, V.S., 2014. Embedded Image Capturing System Using Raspberry Pi System Abstract :, 3(2), pp.213-215.

Shilpashree, K.., Lokesha, H. \& Shivkumar, H., 2015. Implementation of Image Processing on Raspberry Pi. , 4(5), pp.199-202.

Vala, H.J. \& Baxi, P.A., 2013. A Review on Otsu Image Segmentation Algorithm. , 2(2), pp.387-389.

Zhu, Z. \& Ma, M., 2011. The identification of white fertile eggs prior to incubation based on machine vision and least square support vector machine. , 6(12), pp.2699-2704. 